\title{
Leitura de charges: questões metodológicas
}

\author{
Reading cartoons: methodological issues
}

Tamiris Machado Gonçalves ${ }^{1}$

Aluna de doutorado no curso de Pósgraduação em Letras da PUCRS, área de concentração em Linguística. Bolsista CNPq.

E-mail: mtamiris@gmail.com
RESUMO: A charge é um discurso complexo que se utiliza de vozes sociais contemporâneas a ela para edificar-se como gênero. Este artigo tem como tema a compreensão da charge sob a perspectiva do Círculo de Bakhtin, sobretudo das noções de signo ideológico, gêneros discursivos e vozes sociais. Construindo com a psicolinguística uma interface para entender os processos cognitivos implicados na leitura desse gênero, busca-se também o entendimento do conceito de compreensão leitora. Ademais, são apresentadas informações acerca do Google Formulários, tecnologia on-line que permite a construção de atividades envolvendo charges. A partir do estudo de duas charges de Latuff, publicadas uma em 2014 e outra em 2015 no endereço eletrônico Sul 21, busca-se entender a atividade enunciativa que as constitui: quais recursos são mobilizados para a edificação de seus sentidos. Para tanto, verifica-se como se dão as relações dialógicas entre as charges e os enunciados anteriores que com elas se relacionam para se constituir como gênero na cadeia da comunicação discursiva. Com as discussões em torno dos sentidos construídos, será possível perceber que todo discurso é dialógico, isto é, todo discurso estabelece uma necessária relação com outros discursos, desencadeando diferentes sentidos.

Palavras-chave: Charge jornalística; Construção de sentidos; Interface teórica

ABSTRACT: The cartoon is a complex discourse that uses contemporary social voices in order to edify itself as a genre. This article focuses on the understanding of charge from the perspective of Bakhtin Circle, especially on the notions of ideological sign, genre and social voices. Establishing an interface with psycholinguistics to understand the cognitive processes involved in reading the former genre, the aim is also the understanding of the concept of reading comprehension. In addition, information is presented about Google Forms, online technology that allows the construction of activities involving charges. From the study of two cartoons of Latuff, published one in 2014 and another in 2015 on the website Sul 21 , it seeks to understand the enunciative activity that constitutes itself: what resources are mobilized for the edification of its senses. Therefore, it verifies the dialogical relations between the cartoons and the previous statements that related to them to be constituted as a genre in the chain of discursive communication. With discussions around the constructed meanings, it will be possible to realize that every discourse is dialogic, that means, all discourse establishes a necessary relation to other discourses, initiating different meanings.

KEYwoRDS: Journalistic cartoons; Meaning construction; Theoretical interface 


\section{Introdução}

interesse pela compreensão da charge teve sua origem em uma dissertação de mestrado intitulada "Vozes sociais em confronto: sentidos polêmicos construídos discursivamente na produção e recepção de charges" ${ }^{1}$, defendida em janeiro de 2015. Nessa investigação, foram analisadas charges polêmicas. Explorou-se como se edifica o sentido especificamente em charges que apresentam divergência entre o possível efeito de sentido pretendido pela articulação dos elementos verbo-visuais da charge e as leituras realizadas por seus interlocutores.

O caminho de investigação percorrido na dissertação aumentou o interesse por esse objeto. Assim, este artigo apresenta uma proposta de atividade a partir do gênero discursivo charge. Longe de ser uma receita, o instrumento desenvolvido configura-se como uma sugestão $0^{2}$ de trabalho com charge a partir das orientações metodológicas baseadas nos pressupostos bakhtinianos - especialmente nos conceitos de gêneros discursivos, signo ideológico e vozes sociais. Propondo uma interface teórica, foram utilizadas também tecnologias, procedimentos de pesquisa e aplicação à linguagem, da psicolinguística, a partir dos escritos de Pereira (2012; 2009) e Smith (1999; 2003).

De modo a orientar o profissional que ingressa na carreira docente, o instrumento que aqui se apresenta é destinado a alunos de graduação em Letras, sobretudo àqueles que estão em vias de seu estágio docente; claro que pode também ser utilizado por professores em geral. O intuito foi desenvolver um instrumento, utilizando a tecnologia de formulários on-line para fomentar os saberes docentes de alunos de graduação em

\footnotetext{
Disponível em: <http://repositorio.pucrs.br/dspace/bitstream/10923/7160/1/000466609-Texto\% 2BCompleto-0.pdf>.

2 Como tal, foi elaborado com base em discursos atuais à época de sua composição. No fazer docente, portanto, o professor pode inspirar-se para compor suas atividades, mas tem de buscar discursos contemporâneos ao momento em que for trabalhar com charges.
}

Letras, no que tange ao trabalho com charges desde um ponto de vista dialógico em interface com a Psicolinguística, isso porque não há materiais que proponham especificamente esse recorte.

Como objetivos busca-se a) entender a atividade enunciativa que constitui duas charges de Carlos Latuff, publicadas uma em 2014 e outra em 2015 no endereço eletrônico Sul 21, quer-se especificamente entender quais recursos são mobilizados para a edificação de seus sentidos; e b) compreender o caminho percorrido pelo leitor para construir os sentidos veiculados nas charges selecionadas. Dessa maneira, as análises realizadas propõem uma discussão em torno das charges, de modo que as atividades apresentadas foram desenhadas a fim de que, por meio de protocolos verbais, seja possível identificar os processos cognitivos do leitor no que tange à compreensão leitora do gênero em questão.

Para alcançar os objetivos propostos, verifica-se como se dão as relações dialógicas entre as charges e os enunciados anteriores que com elas se relacionam para se constituir como gênero na cadeia da comunicação discursiva. Nesse sentido, os enunciados com os quais as charges estão relacionadas são apresentados ao leitor por meio de citação ou recorte de fatos sociais contemporâneos às charges a fim de que se possa ter o entendimento global da charge meio a seu contexto de aparição.

Com as discussões em torno dos sentidos construídos, será possível perceber que, conforme a teoria bakhtiniana, que subsidia esta reflexão, todo discurso é dialógico, isto é, todo discurso estabelece uma necessária relação com outros discursos, desencadeando diferentes sentidos. Outra questão é que há um procedimento específico para realizar a leitura de charges, já que o leitor tem de mobilizar necessariamente conhecimentos prévios (gerais), como aqueles que dizem respeito ao código verbal e não verbal, e específicos (pontuais), como identificar os discursos sociais com os quais a charge está dialogando. 
Justamente o que particulariza a charge é que, muitas vezes de modo velado, ela recupera valorativamente temas da atualidade que, se não identificados pelo leitor, prejudicarão o entendimento dos sentidos veiculados, especialmente quanto ao seu projeto enunciativo de estabelecer uma crítica sobre um dado tema. Dessa maneira, necessariamente o leitor tem de estar a par dos diálogos entre os discursos sociais. Por outro lado, o leitor necessita do conhecimento formal da língua para adentrar na crítica edificada, em muitos casos, nos jogos de linguagem como: trocadilhos, metáforas, sentidos contextuais.

Além desta introdução, este artigo apresenta quatro seções: duas de referencial teórico; uma acerca da tecnologia utilizada como sugestão de trabalho; e uma de análise do objeto de pesquisa, as charges de Latuff. A primeira seção, intitulada $O$ dialogismo como perspectiva teórica para a análise de charges, discorre sobre as ideias do Círculo de Bakhtin necessárias à compreensão do discurso chargístico. Dessa maneira, a noção de gênero de discurso é evocada nos moldes que aparece na teoria do Círculo ao mesmo tempo em que é compreendida no entendimento dos contornos da charge. As noções de signo ideológico e vozes sociais são trabalhadas a fim de que seja possível adentrar na criticidade que o gênero requer, no intuito de que seja estimulado um ensino de leitura que passa do nível linear ao profundo.

A segunda seção, intitulada Processamento de leitura: vendo a charge sob o viés da psicolinguística, aborda noções de psicolinguística destacando os conceitos que fundamentam a leitura das charges apresentadas, como é o caso das noções de compreensão leitora, processamento cognitivo e estratégias de leitura. Assim sendo, o foco será a compreensão dos processamentos cognitivos necessários à compreensão desse gênero. Nessa seção, são apresentados autores que discorrem sobre as principais referências da área, isto é, leitores com vasta experiência, bem como produção de artigos e livros em psicolinguística. Esse fato se dá em razão de que o artigo que aqui se edifica tem seu foco na teoria bakhtiniana - por isso toma a escrita direto de traduções dos textos do Círculo - e a psicolinguística entra como área de interface, que fornece noções pontuais para o objetivo proposto: o trabalho com a charge em sala de aula a partir do uso da tecnologia dos formulários on-line.

Em seguida, é apresentada uma seção sobre o Google formulário, uma ferramenta tecnológica oferecida pela plataforma Google. Depois, na seção o discurso chargístico: sugestão de análise, apresenta-se a aplicação dos referenciais abordados já tramados na atividade de trabalho proposta. No segmento final deste texto, são expostas as considerações finais, que se prestam a dar uma conclusibilidade que possibilite a atitude responsiva daqueles que queiram dialogar com este material de reflexão.

\section{0 dialogismo como perspectiva teórica para a análise de charges}

Presente no cotidiano, em jornais, revistas, sites e redes sociais, a charge é um gênero discursivo que estabelece diálogo com discursos que lhe são contemporâneos. Em sua natureza, portanto, há uma trama de vozes que recuperam fatos sociais para edificar seus sentidos e constituir-se como um discurso social na cadeia comunicativa.

Como orienta o Círculo de Bakhtin, todo o discurso é dialógico, assim sendo, mantém relação orgânica com discursos anteriores que lhe servem de base, ao mesmo tempo em que, é projeção para discursos-resposta, dando continuidade à comunicação discursiva. 0 princípio dialógico é base para a construção dos sentidos.

Essa é a realidade de qualquer discurso, mas parece que na charge esse movimento é mais aparente, ou - pelo menos - o interlocutor, para alcançar os sentidos em circulação, tem de estar a par do diálogo que a charge 
estabelece com discursos outros. Identificando as vozes que atravessam a charge - os fatos sociais que são evocados pelos elementos verbais e visuais -, o interlocutor pode, a partir dos elementos que compõem o discurso chargístico, entender a valoração pretendida pelo seu projeto de dizer e dar lugar à compreensão e à interpretação - não ficando somente no nível da opinião pessoal.

A charge pode ter, naturalmente, vários efeitos de sentido, como humor, ironia, sátira, protesto, mas seu projeto enunciativo, geralmente, gira em torno de estabelecer uma crítica, nem sempre aparente, sobre determinados temas sociais. É oportuno mencionar que a palavra crítica, no que tange à charge, está atravessada por uma entonação apreciativa, de juízo de valor - no sentido de ser sempre a valoração de um locutor sobre o mundo em que está inscrito - e não entonação de censura ou depreciação -, conforme Gonçalves (2015, p. 8).

A questão da valoração que os enunciados podem assumir advém de sua relação com o contexto enunciativo em que aparecem. Volochínov ([1926] 2011, p. 154-55) afirma que a palavra está integralmente ligada a seu vínculo extraverbal porque, na vida, ela não é autossuficiente. Ela depende do extraverbal que lhe tenha motivado e com ele mantém conexão - que é justamente o que lhe confere tonalidades, no sentido emotivo-volitivo de estar repleta de valores.

Assim, as valorações de uma palavra estão relacionadas a três aspectos da situação extraverbal, a saber: o horizonte espacial compartilhado (a situação interativa in locu dos falantes), o conhecimento e a compreensão comum da situação (o ato, por parte dos envolvidos, de inteirar-se do tema, isto é, inteirar-se em relação àquilo de que se está falando) e a valoração compartilhada (a percepção dos juízos atribuídos a determinado tema). Esses aspectos indissoluvelmente relacionados à dimensão verbal e visual, no caso da charge, dão a orientação dos possíveis sentidos veiculados.
É a noção de valoração, essa particularidade axiológica que carrega os elementos do discurso, que justifica adjetivar o signo como signo ideológico. Na teoria do Círculo de Bakhtin, como lembra Faraco (2009, p. 45-47), ideológico tem caráter valorativo, por isso não é entendido como mascaramento do real, uma acepção recorrente para o termo.

No signo ideológico, acontece um duplo movimento que requer do interlocutor a compreensão de elementos reiteráveis e não reiteráveis. Isto porque o signo ideológico está apoiado em uma significação dada, com estabilidade linguística instituída socialmente, e, ao mesmo tempo, o signo ideológico preenche-se de informações novas, que criam sentidos contextuais, dependentes de elementos extraverbais. Nesses termos, o discurso atualiza o signo, possibilitando a veiculação dos sentidos no entrecruzamento de dados reiteráveis e novos.

Se o dado é o reiterável, o idêntico, socialmente fixado, o novo é uma característica que o signo obtém na relação com sua materialidade discursiva, imerso na relação eu-outro inscrita em um tempo e um espaço determinados. Isso implica dizer que os signos possuem significação (elementos idênticos, com conteúdo conhecido e evocado da mesma maneira na enunciação) e sentido (aspecto novo, edificado no momento da enunciação concreta, como um fenômeno histórico, carregado de nuances criadas naquele momento, a partir de relações verbais e extraverbais pontuais).

Ao sentido do discurso, Bakhtin/Volochínov ([1929] 2009, p. 133) chamou tema. $\mathrm{O}$ autor explica que o tema é não reiterável, pois "se apresenta como a expressão de uma situação histórica concreta que deu origem à enunciação". 0 interessante é que o tema de uma enunciação, seu sentido pontual e concreto, é determinado pelas formas linguísticas em relação com os elementos extraverbais da situação. Nas palavras de Bakhtin/Volochínov, "se perdêssemos de vista os elementos da situação, estaremos tampouco 
aptos a compreender a enunciação como se perdêssemos suas palavras mais importantes" (ibidem, p. 134).

Além da noção basilar de situar o discurso em um paradigma dialógico e compreender que as formas linguísticas de um discurso qualquer estão entrelaçadas a sua situação enunciativa - justamente porque essa lhe dispõe o extraverbal -, de acordo com Faraco (2009, p. 13), são considerados eixos nucleares do pensamento bakhtiniano a unicidade do ser e do evento, a não separação do mundo da teoria do mundo da vida, a relação eu/outro e a dimensão axiológica inerente ao ser humano (ibidem, p. 18).

Vejam-se algumas dessas afirmações. Quando é colocada a questão da unicidade do ser e do evento, há a necessidade de se compreender que na subjetividade está o ato único, irrepetível, singular; o ser é entendido como um evento único. Nesses termos, como lembra Bubnova (2015, p. 13-14) o ato é único e irrepetível porque é a vivência íntegra do ser em determinada atividade humana. A teoria do ato é o acontecer concreto da existência do ser. Ato é todo o agir humano, um agir orientado e responsável: orientado porque projeta um outro ao qual se dirige, desenhando um discurso nos moldes dessa projeção, e responsável porque surge em condições específicas e sobre a assinatura de um autor situado em um tempo e um espaço definidos.

Na relação eu/outro também perpassa a questão da unicidade do ser e do evento. A singularidade é, pois, sempre plural. Da relação eu/outro advêm nossas particularidades, já que o ser se constitui sempre por meio das relações sociais. É na interação eu/outro que se constrói o sujeito; é por meio da alteridade que ele se reconhece. Isso acontece porque o eu e o outro configuram diferentes universos axiológicos que dão diferentes perspectivas à maneira como cada um observa o mundo. Nesse momento

$\overline{3}$ Em prólogo do livro Yo también soy (fragmentos sobre el outro). já se está tratando da dimensão axiológica que compõe o ser humano, ou seja, o universo de diferentes valores em que o sujeito está circunscrito.

Bubnova (2015, p. 8-13) esclarece que em qualquer âmbito da atividade humana o que define o ser é a relação com o outro no ato criador. Esse entendimento coloca a alteridade como centro do pensamento bakhtiniano. Para a autora, toda a filosofia de Bakhtin edifica-se meio às relações que o eu estabelece com o outro; o outro é a primeira realidade com a qual o eu se encontra no mundo e a partir da qual percebe o mundo mediante em um jogo em que as regras são estabelecidas em função da presença do outro. $\mathrm{O}$ outro é a primeira condição para o surgimento do $e u$, porque seu excedente de visão em relação ao mundo e em relação a si o faz perceber tudo o que ele não pode desde sua posição. Nessa ótica, as atividades desenvolvidas no mundo se dão na estrita relação eu-outro: as atitudes do eu repercutem no outro, são direcionadas a ele. Essa interação é, por sua vez, geradora de um sistema de valores, importante para a construção dos sentidos veiculados pelos parceiros da comunicação discursiva.

Nessa perspectiva, o diálogo é eixo norteador da teoria do Círculo. No entanto, quando se fala nessa noção não se está abordando o diálogo como simples interação face a face entre falante e ouvinte; como forma composicional, como os diálogos de um romance, por exemplo; ou ainda como modo de resolução de conflitos. Para além dessas questões, o diálogo é visto como um movimento de tensas relações de sentido. Diálogo em sentido restrito é apenas uma das manifestações dialógicas que está contida na proposta de diálogo no sentido amplo: as complexas relações sociais e as valorações que delas emanam. Bakhtin/Volochínov afirma que

[...] o diálogo, no sentido estrito do termo, não constitui, é claro, senão uma das formas, é verdade que das mais importantes, da interação verbal. Mas pode-se compreender a palavra "diálogo" num sentido amplo, isto é, não apenas como a comunicação face a face, mas toda comunicação verbal, de qualquer tipo que seja (BAKHTIN e VOLOCHÍNOV [1929] 2009, p. 127). 
Dessa forma, o pensamento bakhtiniano está fundado no dialogismo, esse princípio constitutivo do discurso, da linguagem, do sentido, do sujeito. Nas interações que acontecem no curso do tempo, em um espaço social definido e sob um complexo ambiente de intercursos socioculturais é que o dialogismo tem lugar, porque a relação com o outro é constitutiva.

Bakhtin ([1975] 2002, p. 88) enfatiza que a natureza dialógica é um fenômeno de todo discurso, pois em "todos os seus caminhos até o objeto, em todas as direções, o discurso se encontra com o discurso de outrem e não pode deixar de participar, com ele, de uma interação viva e tensa". Assim, podemos dizer que o sujeito está inserido em uma complexa sociedade rodeada por discursos, com os quais está em permanente diálogo.

A compreensão da linguagem como um processo dialógico inconcluso que requer a permanente relação com o outro só pode existir no momento em que há o entendimento de que a linguagem é produto da atividade humana em sociedade. Isso porque a linguagem é constituída de enunciações que estão no meio social, que são a materialização verbal de sujeitos localizados em um tempo e um espaço definidos. A enunciação acontece a partir da inter-relação entre enunciações de sujeitos históricos. Sendo assim, não há enunciado inédito ou isolado, todo o enunciado se relaciona com outros que o antecedem ou o sucedem. Para Sobral (2009, p. 33),

[...] o conceito de dialogismo, vinculado indissoluvelmente com o de interação, é assim a base do processo de produção dos discursos e, o que é mais importante, da própria linguagem: para o Círculo, o locutor e o interlocutor têm o mesmo peso, porque toda a enunciação é uma 'resposta', uma réplica, a enunciações passadas e a possíveis enunciações futuras, e ao mesmo tempo, uma 'pergunta', uma 'interpelação' a outras enunciações: o sujeito que fala o faz levando o outro em conta não como parte passiva mas como parceiro - colaborativo ou hostil - ativo.

O dialogismo, por conseguinte, é condição para a linguagem e para a constituição do sujeito como ser social. Isso porque é a partir das interações com outros seres sociais que se tem contato com a linguagem, a partir dos usos nas mais diferentes situações comunicativas a que se está exposto os sujeitos vão se constituindo. O dialogismo é alicerce da linguagem, dos discursos, do ser, pois não há nenhuma dessas noções senão por meio da relação de diferença com o outro.

Nessa concepção, a noção de linguagem/língua é entendida como um fenômeno vivo que se nutre do contínuo desenvolvimento social. Esse movimento dá-se sempre no processo de relação entre sujeitos, a partir dos intercursos comunicativos que elaboram os mais diversos tipos de enunciações, correspondentes aos diferentes tipos de intercâmbios comunicativos, isto é, as distintas maneiras de comunicação discursiva advindas do meio social. Os tipos de intercâmbios comunicativos constroem, organizam e completam, a partir de si, a forma composicional e o estilo dos tipos relativamente estáveis de enunciados, a saber, os gêneros do discurso.

Os enunciados são a língua em uso, são uma forma de ação/atitude, são, por isso, a unidade real da comunicação humana. Os enunciados refletem as condições específicas e as finalidades de cada referido campo não só por seu conteúdo temático e pelo estilo, mas, acima de tudo, por sua construção composicional.

Assim, conteúdo temático, estilo e construção composicional estão indissoluvelmente ligados no todo do enunciado e são igualmente determinados pela especificidade de uma determinada esfera comunicativa. Conforme Bakhtin ([1979] 2011, p. 262), "cada campo de atividade tem seus tipos relativamente estáveis de enunciados, que denominamos gêneros de discurso".

A riqueza e a diversidade dos gêneros são infinitas porque são inesgotáveis as possibilidades de atividades verbais de interação (ibidem, p. 262). Conforme crescem e se complexificam as esferas discursivas, os gêneros acompanham esse movimento. Dessa maneira, os gêneros do 
discurso são heterogêneos porque a atividade humana assim o é. Tantos tipos relativamente estáveis de enunciados irão surgir quanto mais forem surgindo mudanças nos modos de enunciar e tantos forem os propósitos comunicativos.

Nesse sentido, o estilo está ligado ao enunciado e às formas típicas de enunciados (gêneros do discurso) porque há maneiras específicas de se arranjar os elementos no discurso. No que tange ao estilo, há aspectos individuais e aqueles relativamente estáveis, caracterizando o primeiro como estilo individual e o segundo como o estilo do gênero.

Em cada campo existem e são empregados gêneros que correspondem às condições específicas de dado campo; é a esses gêneros que correspondem determinados estilos (do gênero) ligados aos campos de atividade. Bakhtin ([1979] 2011) explica que "os gêneros do discurso são correias de transmissão entre a história da sociedade e a história da linguagem" (ibidem, p. 268) justamente porque contêm em si modos de interação discursiva de determinada época. Para o autor, "se a língua entra na vida e a vida entra na língua por meio dos enunciados (ibidem, p. 264-265)”, é através dos gêneros que acontece a dinâmica da linguagem. É por meio de gêneros que se vai tomando conhecimento da própria língua.

A história da linguagem está vinculada à história da sociedade porque a linguagem é constituída nos e pelos usos de determinada sociedade. Nas palavras do autor russo, "nenhum fenômeno pode adentrar a língua sem antes ter passado por um longo caminho de elaboração e experimentação de gêneros" (ibidem, p. 266).

Nos limites deste artigo, as noções bakhtinianas apresentadas demonstram que, para ler determinado gênero, é necessário que se compreendam as relações dialógicas que edificam seus possíveis sentidos. Dessa maneira, a compreensão do gênero charge, por exemplo, passa necessariamente pela identificação da relação eu-outro nos limites de um tempo e espaço definidos. Assim, é possível encontrar os fios dialógicos que tramam seus sentidos e compreender valorações sociais em jogo a partir do vínculo entre elementos verbais e não verbais, de modo a perceber o dado e o novo.

Após a explanação de noções convenientes às análises que serão apresentadas, passa-se à exposição de conceitos da psicolinguística, importantes para compreender a charge na interface teórica proposta.

\section{Processamento de leitura: vendo a charge sob o viés da psicolinguística}

Em texto intitulado Psicolingüística, Balieiro Jr. (2003, p. 171) menciona que "[...] consultem-se fontes diferentes sobre a Psicolingüística e obter-seão delimitações às vezes tão diferentes que é mesmo possível que se estejam falando de coisas diferentes"; comparemos, por exemplo, diz o autor, Golbert (1988) e Kess (1992). Nesse sentido, ele explica que psicolinguística pode ser um campo de estudos, uma disciplina ou um conjunto de pesquisas, a depender do referencial que se adote.

Para Slama-Cazacu (1973, p. 33), a psicolinguística é uma metodologia interdisciplinar, uma disciplina que possibilita abordar um fenômeno de ângulos de visões limítrofes. A autora explica que, no escopo da psicolinguística, encontra-se a comunicação como fenômeno global: "[...] a relação bilateral entre os participantes, o código - lingüístico e nãolingüístico -, as complexas determinantes sociais, as organizações estruturais dos signos, da mensagem, dos contextos nos quais circulam mensagens [...]" (ibidem, p. 38).

Nesse sentido, Slama-Cazacu (ibidem, 59) explica que, no que tange à linguagem, compreender não é apenas aceitar os fatos da linguagem por si, senão apreender determinado valor no âmbito de um todo constituído 
de relações explícitas e implícitas: os signos são emitidos em um momento determinado por alguém específico. Assim sendo, a compreensão é um processo que ultrapassa a expressão em si porque se relaciona com a "personalidade do emissor".

Frank Smith (1999), em seu livro Leitura significativa, esclarece que o ato de ler está para além dos olhos porque relaciona, ademais dos conhecimentos formais acerca de tudo que permite ler (conhecer o alfabeto, entender as informações fonético- fonológicas, ser capaz de decodificar, buscar o sentidos com base nos significados explicitados na superfície textual), há a compreensão do mundo; de determinado texto em relação com seu contexto; há todo o trabalho orgânico que conta com a ajuda das memórias de longo e curto prazo, da atenção; há a impressão intelectual de compreender-se o leitor frente a um processo ativo, participante da construção dos sentidos. Todos esses elementos indicam que a compreensão de qualquer discurso não é responsabilidade exclusiva nem do autor nem do leitor.

Compreender, isto é, ler significativamente, é um ato dinâmico, possível a partir da combinação de diferentes fatores. 0 ensino da leitura, dessa forma, tem de determinar em que paradigma está ancorado para poder tramar uma rede que possibilite entender o próprio objeto leitura. Assim sendo, toda a estratégia que visa a inserir o aluno no universo da leitura estará, de antemão, direcionada no entendimento que se tem do que é ler efetivamente. O professor que almeja a leitura como reflexão, jamais pode, por exemplo, usar exclusivamente atividades que visem ao preenchimento de informações pontuais, que indaguem somente conhecimentos linguísticos ou estejam baseadas na opinião do aluno no sentido de julgar se lhe agradou ou não a leitura.

A proposta de trabalhar com charges está aqui embasada em uma perspectiva que entende leitura como ato dinâmico, tanto no sentido de demonstrar que diferentes ângulos compõem o processo de construção de sentidos, como no intuito de explicitar que explorar compreensão leitora em sala de aula é formar leitores críticos, cientes dos discursos sociais de seu tempo. Nas palavras de Smith (2003, p. 198), a leitura nunca é, ou nunca deve ser, "uma atividade abstrata, sem finalidade [...]. Os leitores sempre leem algo com uma finalidade; a leitura envolve [...] emoções, bem como conhecimento e experiência". Ao encontro dessa afirmação, entende-se a leitura de charges.

Tendo em vista tais considerações, neste artigo, entender os processos cognitivos no que concerne à leitura no espectro das pesquisas advindas da grande área da psicolinguística forma com a teoria bakhtiniana um fértil aporte para o trabalho com a charge. Dentre as definições de leitura, estamos de acordo com Colomer e Camps (2002, p. 32), quando afirmam que a leitura é "uma tarefa complexa que depende de processos perceptivos, cognitivos e linguísticos". Nesse sentido, o ato de ler implica um processo ativo que relaciona o que está posto no discurso, os possíveis sentidos pretendidos pelo autor, os contextos que motivaram tal produção e como o leitor enquanto sujeito no mundo se coloca frente a tudo isso.

Especificamente sobre compreensão leitora, Pereira (2012, p. 82) explica que essa capacidade, do ponto de vista da psicolinguística, é entendida como o processamento realizado pelo leitor para apreender o conteúdo lido. Nesse sentido, importa examinar os caminhos que o leitor fez para encontrar os sentidos que achou em determinado discurso. Em quais elementos esteve ancorado? Quais conhecimentos prévios mobilizou para entender x e não y?

A leitura da charge aqui está ancorada, ademais da teoria bakhtiniana, nos pressupostos psicolinguísticos que entendem leitura como processo cognitivo que se realiza baseado em dois movimentos que se alternam: um linear, minucioso, em que se vai vagarosamente atentando às pistas visuais, um percurso que vai da parte para o todo (ascendente); e outro não linear em que são considerados aspectos da macro para a micro estrutura no sentido de ir do todo para as partes. 
O processamento ascendente (bottom- $u$ ) acontece quando o objetivo é uma leitura minuciosa, necessária, por exemplo, na elaboração de um resumo, comentário crítico, realização de leituras teóricas. Já o descendente (top-down), ocorre quando o intuito é localizar rapidamente determinada informação como a data em uma ficha catalográfica, o preço em um site de produtos à venda, para citar alguns exemplos (PEREIRA, 2009. p. 81).

Necessariamente nesse jogo entram em cena estratégias tais como scanning, que é um mecanismo de leitura utilizado para a apreensão rápida de informação; skimming, que é uma assimilação global, tendo em conta percepções e entendimentos gerais; inferência, estratégia que consiste em fazer deduções a partir de elementos de determinado discurso em relação com seu contexto; predição, antecipação com base nos conhecimentos prévios e com o auxílio das inferências realizadas; testagem de escolhas, estratégia que surge ancorada na predição, uma vez que coloca em teste as hipóteses anteriormente traçadas e avalia as escolhas e os caminhos tomados; entre outras (PEREIRA, 2012, p. 84-85).

Nessa perspectiva, a depender do objetivo, para se alcançar a leitura e a compreensão da charge, por exemplo, é necessário que se intercale essas estratégias a fim de que se conjugue, conforme Pereira (2012, p. 108), conhecimentos específicos - como o conjunto de saberes formais que possibilitam a leitura e os recursos linguísticos que o sujeito leitor dispõe--, bem como a experiência de mundo que ele carrega - o que engloba o conjunto de saberes acerca do conteúdo abordado por determinado discurso.

Como foi dito na seção anterior, a charge é um discurso que se edifica em relação a vozes sociais que são contemporâneas a ela. Organizando um discurso que mobiliza elementos verbais, visuais ou verbovisuais, ela requer que o leitor movimente necessariamente conhecimentos gerais e específicos no que tange à língua e no que diz respeito aos discursos aos quais ela faz referência. Sem o conhecimento dos temas com os quais a charge está dialogando, o leitor não é capaz de chegar à compreensão. Talvez ele decodifique os elementos linguísticos e chegue a alguma conclusão no entendimento deles na relação com os aspectos visuais, mas certamente não será possível compreender profundamente os sentidos veiculados pode inclusive chegar a sentidos diferentes, até discrepantes, dos sugeridos pelos elementos da charge - porque seus conhecimentos prévios sobre a temática não são suficientes. Assim sendo, ele não pode ler a charge em profundidade porque não consegue preencher os vazios que nela se encontram e relacionar as pistas que o encaminharão a estratégias cognitivas de leitura, inconscientes e intuitivas, ou metacognitivas, conscientes e reflexivas.

A leitura da charge implica, como qualquer outro texto, o entendimento de sua publicação dentro de uma circunstância de tempo, sob a assinatura de um autor determinado que a construiu com objetivos específicos - que podem ou não ser identificados pelo leitor. A questão é que, ainda que se leve em consideração todos esses aspectos para encontrar os sentidos da charge, pode ser que se encontrem outros, porque as inferências feitas pelo leitor, seu sistema de crenças envolvido na significação dos elementos do discurso que a ele se apresenta podem ser, de modo geral, diferentes dos que motivaram o autor da charge.

Após essas considerações, tratar-se-á dos formulários Google, uma ferramenta on-line para o trabalho com charges.

\section{Ferramenta tecnológica para o trabalho com charge: formulários Google}

Como a leitura de qualquer discurso não é algo que se possa observar diretamente, pode-se lançar mão de estratégias para perseguir o percurso que o leitor faz para chegar ao entendimento do que lê. Nessa pers- 
pectiva, os protocolos verbais são uma das estratégias possíveis. Para Tomich (2007), os protocolos verbais são ferramentas de pesquisa que viabilizam o acesso aos processos mentais envolvidos, por exemplo, na compreensão leitora.

Dentre os tipos mencionados pela autora (ibidem, p. 43-44), neste artigo integra-se às atividades propostas o protocolo que visa ao autorrelatório, método no qual o leitor mostra sua percepção subjetiva acerca do processamento de leitura. Não importa chegar a uma verdade absoluta, o interessante é que o leitor possa, através das perguntas elaboradas pelo pesquisador, demonstrar como ele acredita agir para compreender determinada leitura.

Outros meios como a escolha simples, múltipla escolha ou distintas formas de questionário são oportunos para verificar a compreensão leitora. No caso da opção por questões de escolha simples, pode-se pontualmente averiguar as inferências realizadas, a identificação dos fios discursivos com os quais determinado discurso foi tramado, reconhecimento dos fatos sociais que o motivaram; distinção de generalidades, particularidades, sentidos contextuais; validades de conclusões; leitura subjacente aos elementos verbovisuais.

Quanto à formulação dos mais variados tipos de questionamentos, nas palavras de Kleimam (2008, p. 56), “[...] formular perguntas é também constitutivo da leitura uma vez que elas são próprias das estratégias de mobilização da compreensão e de estabelecimento de objetivos, estratégias estas necessárias à compreensão e, portanto, necessariamente utilizadas pelo leitor proficiente". Nesse sentido, tanto o pesquisador, professor, pode solicitar que o leitor demonstre seus caminhos traçados na elaboração dos sentidos ou, por outro lado, pode oferecer um rol de questionamentos para verificar a compreensão. De qualquer modo, a formulação de perguntas é prática constitutiva do próprio ato de ler.
Tendo em vista o exposto, uma ferramenta disponível dentro da plataforma Google Drive, o Google Formulários ${ }^{4}$ (Google Foms), permite, entre suas possibilidades de uso, gerar fórmulas para criar ou coletar os mais diversos tipos de dados por meio de diferentes pesquisas. 0 intuito deste artigo é criar um espaço para motivar o trabalho com a charge em sala de aula porque parece oportuno, meio às tantas horas que se vive conectado, utilizar uma ferramenta on-line com fins pedagógicos. Talvez porque a internet constitui, no mais das vezes, ambiente familiar à maioria dos alunos, disponibilizar exercícios nesse espaço possa motivá-los à realização de atividades escolares no ambiente virtual.

Os formulários do Google permitem desenvolver endereços eletrônicos em um nível simples ou complexo. Utilizando as customizações padrão da ferramenta, é possível personalizar perguntas e respostas sem nenhum tipo de conhecimento de programação, apenas fazendo uso dos modelos disponíveis pela própria ferramenta.

Pode-se, por exemplo, especificar o número de respostas, de modo ilimitado a fim de disponibilizar o instrumento para quantas pessoas for necessário. Outra questão interessante é que não há restrição de dispositivo, podendo ser usado no computador, smartphone ou tablet, facilitando a tarefa de que as pessoas respondam às perguntas. Há campos de texto, escola simples, respostas em grade.

É possível mandar a pesquisa por e-mail, permitindo que a pessoa responda ao formulário através de um link que irá direcioná-la ao endereço do formulário criado ou por meio do próprio e-mail, uma vez que o formulário tem a opção de que sua visualização e resposta se deem no corpo do próprio e-mail; anexá-la em um endereço eletrônico já existente, etc.

${ }^{4}$ Disponível em: <https://www.google.com/intl/pt-BR/forms/about/. Pode-se chegar ao Google Formulário também pela plataforma Google Drive, disponível em https://www.google.com/intl/pt-BR/drive/>. 
Figura 1

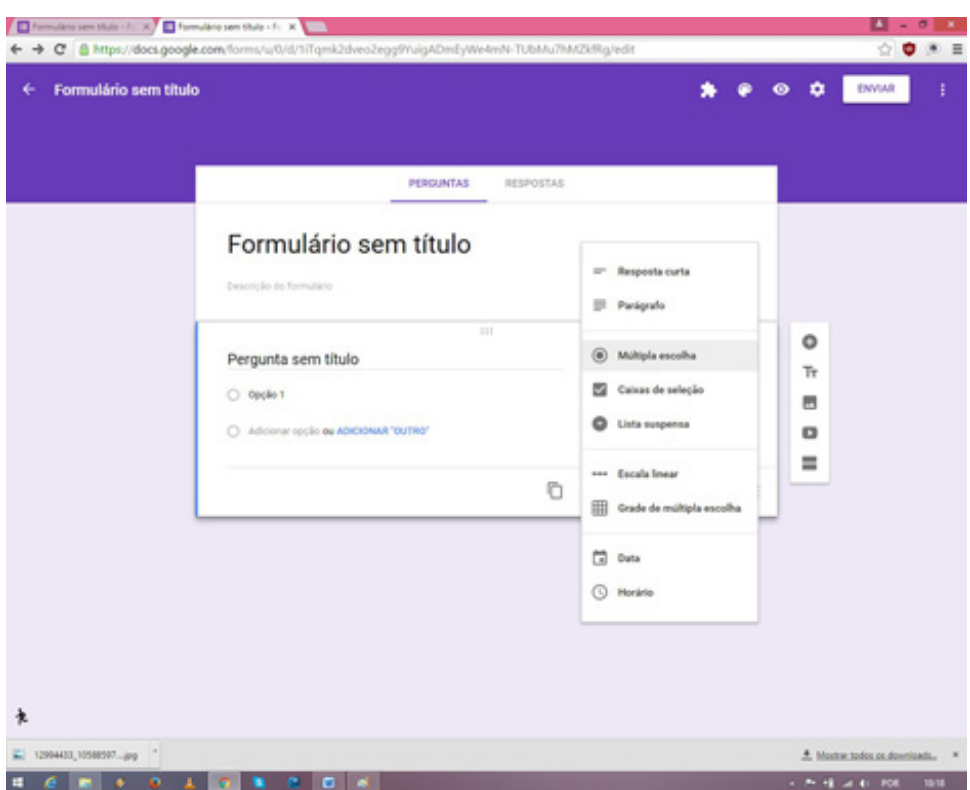

Podem-se acrescentar imagens, vídeos; obrigatoriedade de resposta. Pode-se, ademais, acrescentar scripts para gerar e calcular gráficos de respostas automáticas. Outra marca interessante do formulário do Google é que, como todas as ferramentas da suíte de documentos da empresa, permite trabalho colaborativo. Assim sendo, é possível dividir a tarefa de edição do formulário com mais pessoas, que podem ser adicionadas via e-mail, desde que possuam uma conta Google.

Quanto às analises, é possível gerar relatórios que mostrem as estatísticas a partir das respostas. A coleta de respostas pode também ser armazenada em planilhas tipo Excel, por exemplo. Nesse sentido, é possível acrescentar fórmulas que fazem o desenho dos resultados em diferentes tipos de gráficos.
Figura 2

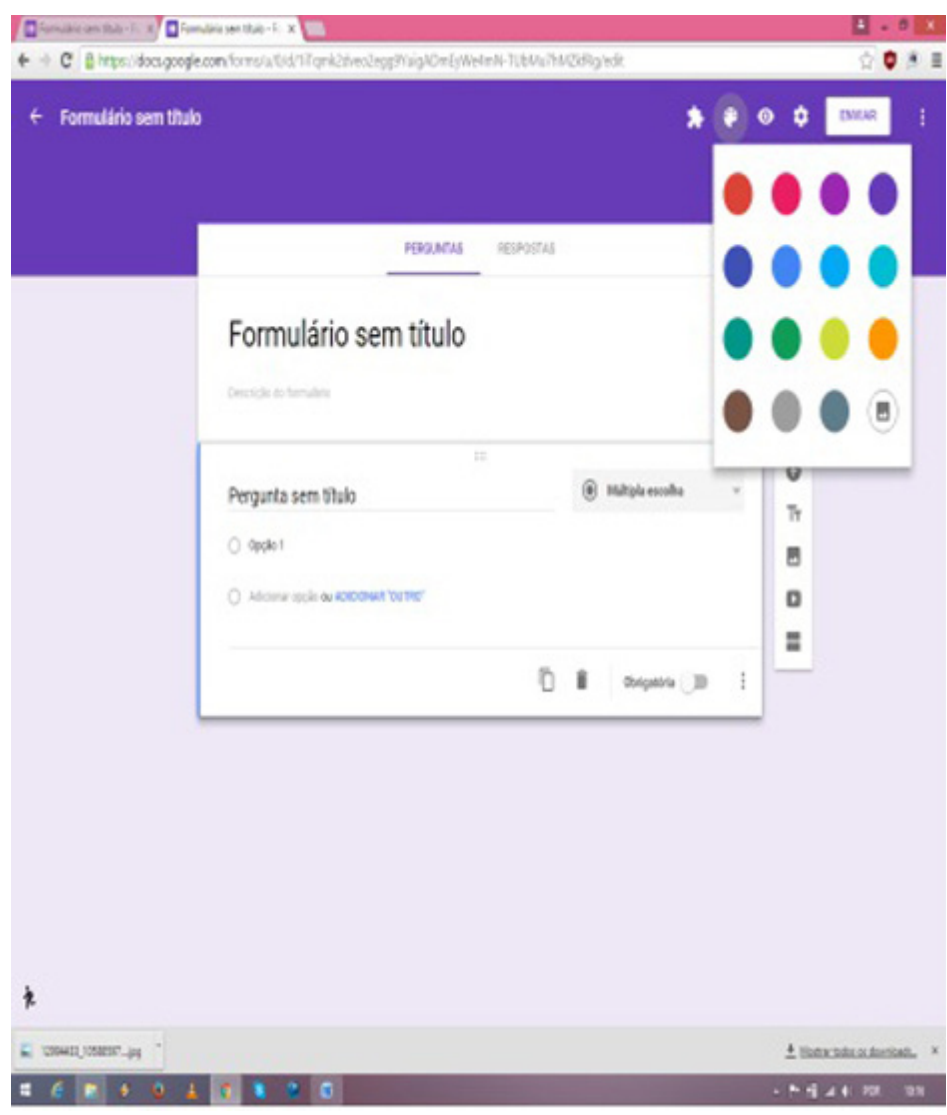

Fonte: Criada pela autora

Por tudo o que foi comentado, a ferramenta on-line Google formulários possibilita que o professor componha um interessante espaço de trabalho com charges (e muitos outros gêneros), tendo à disposição uma interface simples de trabalho praticamente pronta nos motivos que a própria suíte de documentos oferece. 


\section{0 discurso chargístico: sugestão de análise}

Com base nos fundamentos da teoria bakhtiniana, bem como o que foi dito a respeito das noções de psicolinguística e sobre a tecnologia dos formulários Google, é possível ler o gênero chargístico com olhos atentos à crítica que esse discurso veicula. A compreensão da charge por meio das teorias apresentadas permite a visualização das vozes sociais que a compõem, levando o interlocutor a ter uma leitura para além dos elementos aparentes na materialidade discursiva. Assim, ao experienciar uma leitura profunda, pode-se equacionar questões sociais contemporâneas, associar os elementos discursivos presentes na charge aos seus conhecimentos de mundo e à atualidade dos discursos que circulam na sociedade que o circunscreve.

As charges que serão analisadas são de autoria de Carlos Latuff. Publicadas em um veículo de comunicação web colaborativo chamado Sul 21, uma em 2014 e outra em 2015. Sob a motivação de uma temática política, as charges são direcionadas a atitudes da figura pública de José Ivo Sartori, candidato, em 2014, ao governo do estado brasileiro do Rio grande do Sul e, em 2015, governador após ganhar as eleições.

Na primeira charge analisada (Fig. 3), têm-se elementos verbais e visuais que se completam para dar sentido ao discurso. Vê-se a figura de um homem que, de joelhos apoiados no que parece ser a laje de uma marquise e tem a seu lado uma caixa de papelão escrito Tumelero, enuncia "tomaí teu piso" enquanto joga peças de piso em cima da cabeça de uma mulher que aparece segurando uma bandeira de cor amarela com o símbolo do centro e sindicato dos professores do Rio Grande do Sul, o Cpers.

A julgar pelos acontecimentos quando de sua publicação, a charge dialoga com vozes sociais que apontam para um episódio da campanha do então candidato às eleições para o governo do Rio Grande do Sul, José Ivo
Sartori, do Partido do Movimento Democrático Brasileiro - PMDB. Nessa ocasião, outubro de 2014, período eleitoral, em uma entrevista para o Portal de notícias Terra ${ }^{5}$, José Ivo Sartori, ao se manifestar sobre seus projetos eleitorais para a educação, menciona a polêmica quanto ao pagamento do piso salarial dos professores e diz “[...] sim, o piso, eu vou lá no Tumelero e compro, e eles te dão um piso melhor, né?![...]".

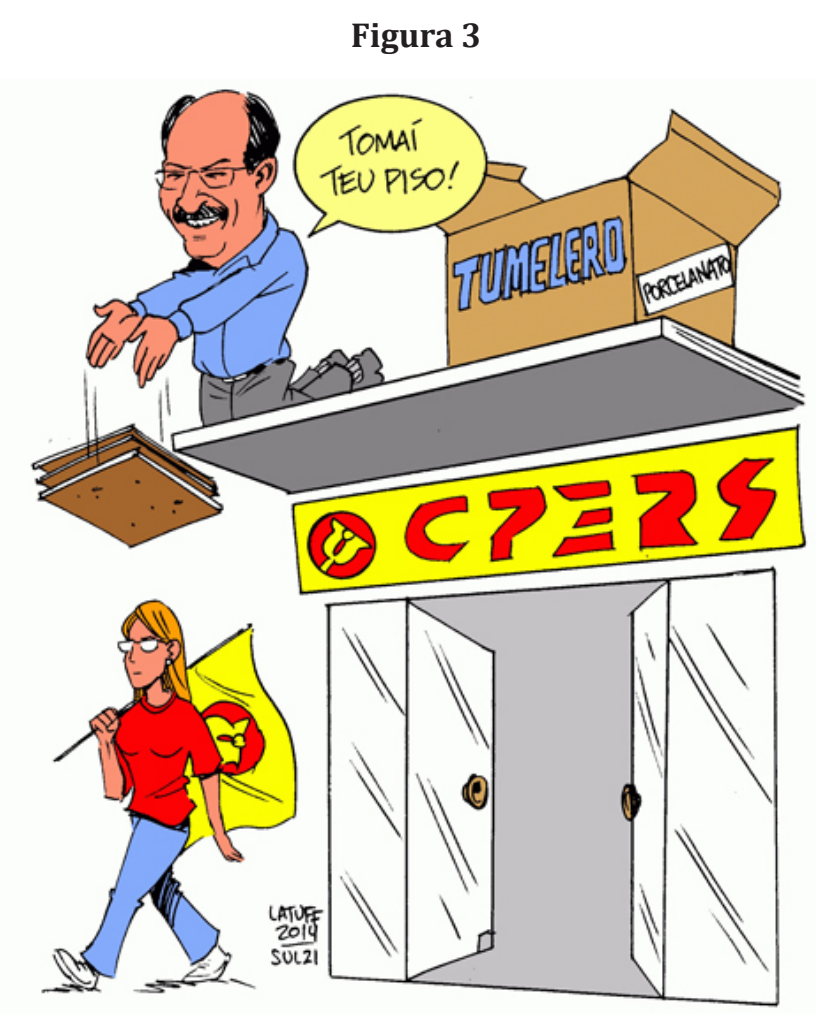

Fonte: <http://media.sul21.com.br/sul21site/2014/10/20141020-sartori-e-o-piso-dos-professores.gif>

${ }^{5}$ A referida entrevista está disponível na íntegra no seguinte endereço eletrônico: <http://noticias. terra combr/eleicoes/videos/sartori-reforca-apoio-a- secio-e-critica-excesso-de-partidos,7654478 html>. Acesso em: 20 out 2015. O referido trecho pode ser acessado na íntegra em: <https: //W Wh.html $>$. com/watch? $\mathrm{v}=0$ siffo $65 \mathrm{cDY}>$. Acesso em: 20 out. 2015 . 
Essa declaração foi alvo de inúmeras contrapalavras ${ }^{6}$ que destacaram a atitude do candidato ao ter sugerido que os professores busquem o direito ao piso salarial do magistério em loja de material de construção. Tudo porque a utilização do signo ideológico piso por parte do político teve um jogo de duplo referente social: a) piso = menor salário pago a um trabalhador dentro de determinada categoria profissional (sentido construído a partir da menção da categoria dos professores); e b) piso = revestimento; acabamento de cerâmica, porcelanato, madeira (sentido construído a partir do signo ideológico "Tumelero", que é uma conhecida rede gaúcha de materiais de construção ${ }^{7}$. Além disso, o signo ideológico "porcelanato" reitera a voz social Tumelero loja de matérias de construção). Nessa perspectiva, tem-se um jogo entre dado (elementos linguísticos = acepções para a palavra piso) e o novo (sentido contextual advindo da relação "tumelero" + "porcelanato" + elementos extraverbais).

Assim, na charge, a caixa de papelão com as palavras "Tumelero" e "porcelanato" aponta para a referência social do signo ideológico piso como acabamento de construção civil, o que é reiterado pelas três peças de revestimento que a figura de Sartori - a julgar pelos traços caricaturais que remetem às feições do político - joga na figura feminina que segura a bandeira do Cpers e, nesse ato, encarna a categoria dos profissionais da educação, representado, de modo geral, em sua maioria por mulheres culturalmente uma profissão predominantemente feminina, ao longo da história da categoria no país.

\footnotetext{
${ }^{6}$ Disponível em: <http://oglobo.globo.com/brasil/em-video-sartori-recomenda-que-professores-busquempiso-em-loja-de-material-de-construcao-14310901>. Acesso em: 18 out. 2015. Disponível em: <http://
veja.abril.com.br/blog/felipe-moura-brasil/2014/10/20/nao-ha-limites-petistas-manipulam-video-deveja.abril.com.br/blog/felipe-moura-brasil/2014/10/20/nao-ha-limites-petistas-manipulam-video-desartori-sobre-piso-dos-professores/>. Acesso em: 18 out. 2015. Disponivel em: <http://politica.estadao. com.br/noticias/eleicoes,candidato-no-rs-sugere-que-professores-pecam-o-piso-em-loja-de-material-de-

7 <http://www.tumelero.com.br/sobre-a-tumelero.php>. Acesso em: 20 out. 2015.
}

Os signos verbais que constituem o enunciado "Tomaí teu piso!" constroem com os elementos visuais o sentido do discurso chargístico. $\mathrm{O}$ dicionário de língua portuguesa Houaiss apresenta que a interjeição toma é utilizada para construir efeito de zombaria. Em "tomaí teu piso" há uma contração da interjeição toma com o advérbio aí, que aponta para o lugar em que se encontra a pessoa com quem se fala. $O$ sinal de pontuação dá a entoação exclamativa, reforçando o tom de chacota - expressado também no traço visual pelo sorriso que a figura masculina sustenta ao jogar o piso.

Socialmente, a contração da interjeição com o advérbio, que dá origem à forma "tomaí", pode também entoar efeito de ironia ao ser proferido quando se dá a alguém algo que por ela fora requerido. Pode-se, ademais, dizer que o forma toma, em "tomaí teu piso", comporta os sentidos de pegar/apanhar, constituindo culturalmente forma grosseira de trato pessoal.

Todos os elementos da charge remetem o interlocutor para a entrevista de campanha do político do PMDB, especificamente quando de seu comentário sobre sua ida ao Cpers e sua manifestação sobre o pagamento do piso - sobretudo com a suposta brincadeira do candidato com a categoria dos profissionais da educação.

Nesse sentido, o interlocutor dispõe de elementos que reiteram a cena enunciativa com que a charge dialoga para edificar-se como discursoresposta. Nessa dinâmica, há o contraste entre os signos piso salarial (evocado pelo signo verbal "CPERS" e pelo signo visual mulher com bandeira) e piso revestimento (evocado pelo signo verbal "porcelanato" e "Tumelero"). Porém, o leitor só pode chegar a essa compreensão quando lê a charge em relação com o mundo, pois esse gênero requer a identificação dos fios sociais que o motivaram - pelo menos para uma leitura profunda que vise a perceber sua crítica.

Nesse jogo de contraste entre os elementos (verbais e visuais) da charge, e sua relação com os discursos contemporâneos a ela, o leitor é capaz de 
compreender que, por exemplo, a caricatura do político encontra-se em cima do prédio do Cpers, porque constrói referencia à menção do próprio candidato que, em sua entrevista ao portal de notícias, informou ter ido até a sede do sindicato para posicionar-se a favor do não pagamento do piso salarial, que, conforme ele, é de responsabilidade de quem prometera o pagamento - entenda-se o governo que estava no poder quando dessa declaração, a saber, Tarso Genro, do Partido dos Trabalhadores - PT.

Assim, a partir dos elementos verbais, dos visuais (em conjunto com a recuperação por parte do interlocutor de toda a cena enunciativa da entrevista de Sartori) e da carga crítica que o gênero charge comporta, pode-se ler (compreender) que a charge de Latuff, ao mesmo tempo em que relembra o interlocutor da declaração do político, denuncia seu não comprometimento com a educação. Isso pode ser capturado a partir da relação entre o enunciado "tomaí teu piso" e o ato de atirar em cima da cabeça da professora as peças de porcelanato.

Note-se que os sentidos delineados estão apoiados na língua (acepções para a palavra signo) e no que o conhecimento de mundo que todo o contexto social de publicação da charge oferece; é nesse vínculo entre dado e novo que há a atualização dos signos ideológicos no discurso. Pelos olhos da psicolinguística, pode-se dizer que compreender o todo no âmbito das relações explícitas e implícitas impulsiona o leitor ativo ruma à compreensão leitora. Por um olhar bakhtiniano, pode-se dizer que o entendimento dos sentidos veiculados, quando se deseja uma leitura profunda, depende da compreensão dos signos com seu vínculo extraverbal (que compreende o horizonte social compartilhado; o conhecimento da situação e a valoração que os colore).

A segunda charge que se analisará (Fig. 4) também é de autoria de Latuff e foi veiculada no endereço eletrônico Sul 21 em janeiro de 2015. Na charge, elementos verbais e visuais se complementam para construir os sentidos.
Vê-se a caricatura do governador Sartori, carregando uma caixa de porcelanato, saindo de uma loja de materiais de construção gaúcha, enunciando, sorrindo, "pago só daqui a seis meses!" enquanto alguém observa com espanto - a julgar pela expressão facial: olhos arregalados e boca aberta - do lado de dentro da loja a ação do governador.

A construção linguística "Pago só daqui a seis meses" apresenta o verbo pagar no presente do indicativo, junto à expressão de futuro "só daqui a seis meses", construindo um jogo de ironia, uma vez que o uso do verbo no presente prepara o leitor para a ação de pagar, mas a expressão de futuro marca o adiamento dessa ação. 0 ponto de exclamação usado nesse anunciado enfatiza o conteúdo da mensagem, por um lado, e, por outro, acentua o traço de ironia. Assim, os aspectos verbais, junto aos elementos imagéticos da charge, na relação com os discursos sociais veiculados quando de sua publicação, permitem ler que o governador assume a responsabilidade da atitude: adiamento do pagamento.

Como se pode perceber, os sentidos advindos dos elementos verbovisuais que compõem o discurso chargístico que se analisa entoam vozes sociais que remetem a um dos primeiros pronunciamentos quando da posse do então eleito com $61,2 \%$ dos votos válidos ${ }^{8}$ na campanha ao governo do estado gaúcho de 2015, José Ivo Sartori. A cena da charge, através do projeto enunciativo de seu locutor, remete o interlocutor ao fato de o governador do RS ter publicado um decreto com uma série de medidas de austeridade como congelamento de concursos públicos, adiamento de nomeações e suspensão do pagamento de fornecedores por seis meses, devido "às graves dificuldades financeiras do estado" - conforme noticiou um dos principais jornais ${ }^{9}$ do RS.

8 Disponível em: <http://eleicoes.uol.com.br/2014/noticias/2014/10/26/sartori-vence-tarso-e-mantemtradicao-de-cemiterio-de-governadores-no-rs.htm>. Acesso em: 21 out. 2015

9 Disponível em: <http://zh.clicrbs.com.br/rs/noticias/noticia/2015/01/piratini-publica-decreto-quecongela-concursos-e-nomeacoes-por-6-meses-4675225.html>. Acesso em: 20 out. 2015. 
Figura 4

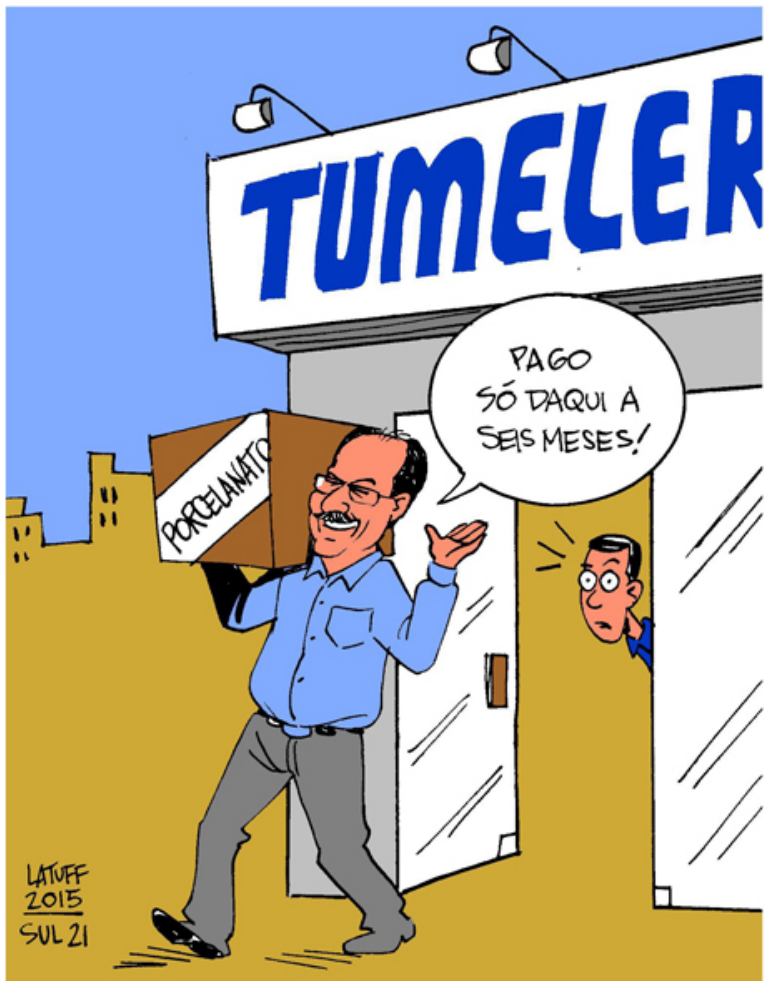

Fonte: <http://www.sul21.com.br/jornal/latuff-e-o-calote-de-sartori/>.

Nesse contexto, o chargista, para edificar sua obra, dialoga com fatos saciais contemporâneos - a época da charge -, mas também retoma, em diálogo, sua charge publicada quase dois meses antes (em outubro de 2014, quando das campanhas eleitorais para o governo do RS).

O enunciado linguístico "Pago só daqui a seis meses!" dialoga com a declaração do político quando de sua posse do governo do estado do RS. O espanto da figura masculina que aparece atrás das portas da loja faz referência ao primeiro comunicado do governador eleito ser o atraso e adiamento das contas do governo.

Em relação, as duas charges criam um personagem baseado nas atitudes do político Sartori. Cumprindo com seu projeto discursivo de ser uma crítica - no sentido de ser o juízo de valor de determinado locutor -, a charge abre a polêmica de colocar as atitudes do político em foco e, por meio de seus elementos, lembra o interlocutor acerca dos discursos de Sartori sobre o piso dos professores gaúchos, já que retoma signos ideológicos como "Tumelero" e "porcelanato", conforme se pode perceber na comparação entre as duas charges na Figura 5.

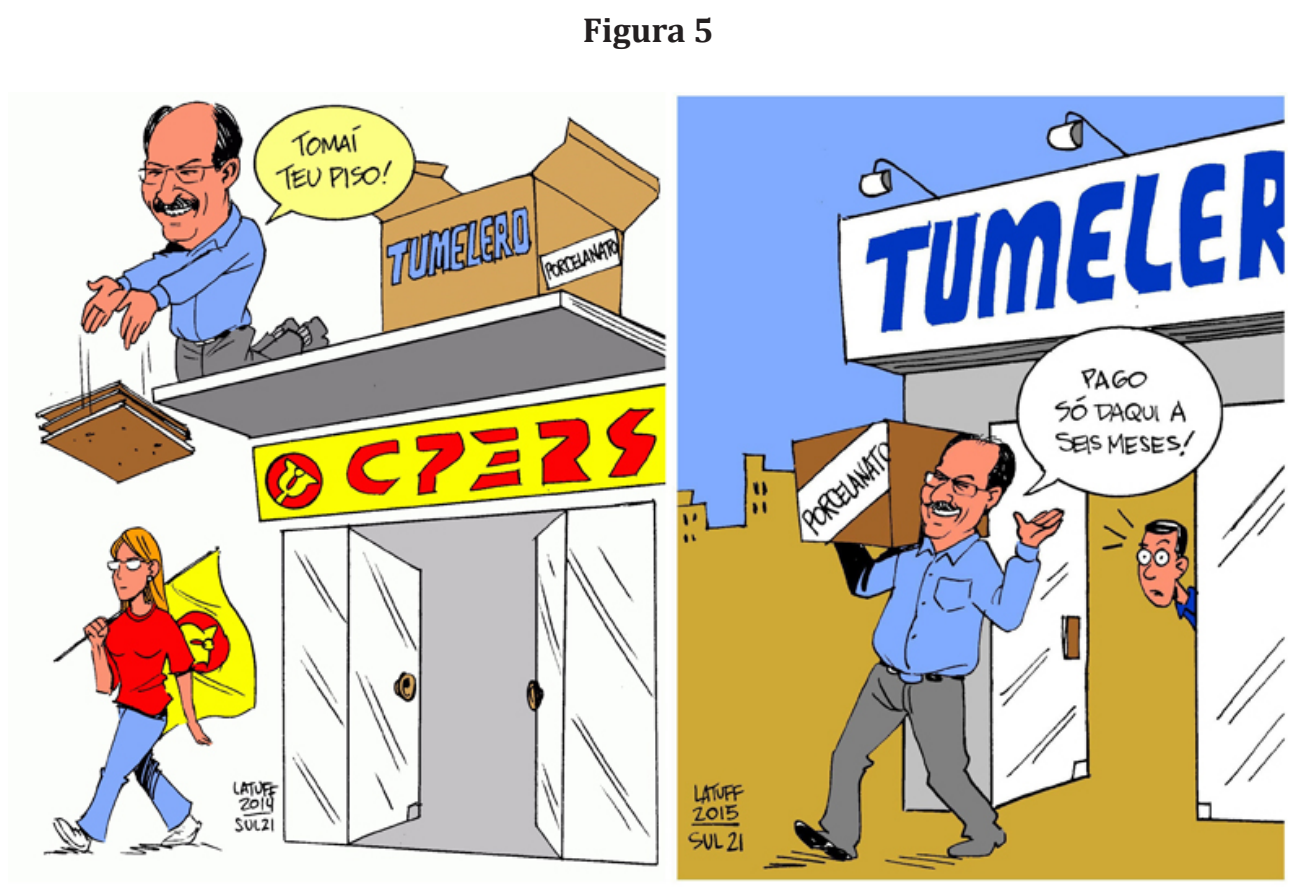

Fonte: Charges de Latuff. 
A partir das análises, pôde-se perceber como se dão as relações dialógicas entre as charges e os enunciados anteriores que com elas se relacionam para se constituir como gênero na cadeia da comunicação discursiva. Também foi possível verificar em que medida as próprias charges do autor se relacionam entre elas.

As considerações aqui levantadas possibilitam ver como os sentidos são construídos nesse gênero discursivo, o que pode configurar reflexões sobre leitura e produção de sentidos em língua portuguesa. Assim, quando se trabalha na escola com charge, tem-se a oportunidade de observar a língua em uso; desenvolver a capacidade leitora e crítica dos educandos; é possível levá-los a perceber que os sentidos contextuais estão apoiados na trama formada por: elementos reiteráveis + fatos sociais + discursos anteriores + elementos extraverbais, que compõem a situação na qual determinado discurso se edifica. Para cada discurso, para cada grupo de alunos, certamente há níveis possíveis de explicitação das relações comentadas aqui.

A partir do arcabouço teórico que sustenta este trabalho, é possível compreender o potencial do gênero chárgico para o ensino de língua materna no que tange ao desenvolvimento das habilidades e competências necessárias em língua portuguesa, de acordo com os Parâmetros Curriculares Nacionais (PCN) e as Orientações Curriculares (OC).

O estudo da charge é uma possibilidade de trabalho em sala de aula porque permite atividades com outros textos, por exemplo, aqueles que a originaram. Com isso, é ampliado o leque de discursos que o professor pode levar para as aulas. Refletindo sobre diferentes discursos, o professor pode motivar a formação crítica de leitores, capazes de se posicionar socialmente e exercer sua cidadania nas variadas esferas de atividade humana.

Desenvolver um ambiente virtual para o trabalho com charges a partir dos Formulários Google dá ao professor a facilidade de lidar com as respostas dos alunos, no sentido de utilizar a computação dos dados para averiguar

quais aspectos da compreensão leitora precisam ser trabalhados e com quais alunos. Isso oportuniza um ensino mais direcionado, capaz de discutir em classe atividades que visem a preencher as lacunas percebidas na análise do processamento da compreensão leitora por meio dos protocolos verbais que o aluno é submetido nos formulários.

\section{Figura 6}

\section{LEITURA DE CHARGES: QUESTÕES} METODOLÓGICAS

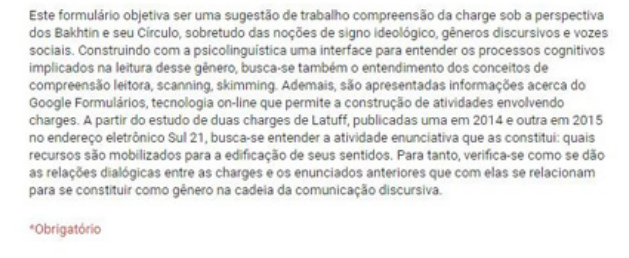

Nesta charge, tem-se elementos verbais e visuais que se completam para dar sentido ao discurso. Vê-se a figura de de uma marquise e tem a seu lado uma caixa de papelāo peças de piso em cima da cabeça de uma mulher que simbolo do centro e sindicato dos professores do estado do Rio Grande do Sul, o Cpers-sindicado.

\section{Charge de Latuff, 2014.}

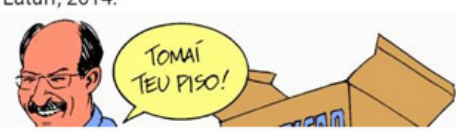
escrito Tumelero, enuncia "tomaí teu piso" enquanto jog

\section{Vocêe}

Explique como você chegou a essa resposta. Em que element linguísticos-discursivos você se apoiou para elaborar su

Sua resposta

A charge em questão recupera dialogicamente discursos de ampla divulgaçăo na midia brasileira. Depois de refletir com quais fatos sociais a charge dialog corretas no que tange a compreensão dessa charge.

$\square$ Tem-se nesse jogo de elementos verbais enăo verbais o ponto de vista um locutor sobre atitides do politico lvo Sartion.

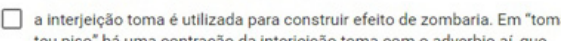

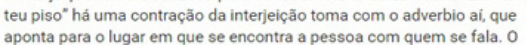
inal de pontuaç̧o dá a entoạçāo exclamativa, reforçando o tom de thacota - expressado tamberm no traco visual pelo sorriso que a figura

$\square$ Socialmente, ainda como interejeiçăo, "tomai" pode também entoar efétio
de ironia ao ser proferido quando se dá a alguém algo que por ela fora

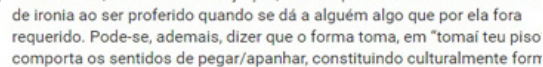
grosseira de trato pessoal.

$\square$ Nenhuma alternativa está correta

PRóxima

Fonte: Criado pela autora.

Questões como "A partir da identificação dos discursos sociais que originam essa charge, indique uma leitura possível. Demonstre em sua explicação em quais elementos discursivos ou extradiscursivos está ancorada a sua resposta" permitem que o leitor volte-se a seu processo de compreensão 
leitora. Isso é importante para gerar uma leitura ativa e autônoma, sem a condução do professor à resposta ideal - claro que isso só é possível quando o estudante já tenha tido um contato mediado com esse gênero (deve haver pelo professor uma instrução formal sobre a leitura crítica de charges, de maneira a orientar o aluno a perceber a relação entre todos os elementos que compõem o discurso chargístico, bem como a identificação dos fios discursivos que relacionam a charge aos fatos sociais, conforme se mostrou nas análises).

Indagações sobre o ato de ler por meio de protocolos verbais de autorrelatório como "Você é capaz de descrever seu processo de compreensão leitora? Explique como você chegou a essa resposta. Em que elementos linguístico-discursivos você se apoiou para elaborar sua resposta?" pode ajudar o professor a entender o processo de compreensão leitora do aluno e ver se ele está conseguindo adentrar ao nível de leitura crítica.

Outra sugestão é trabalhar a compreensão leitora da charge na relação interdiscursiva, abordando a valoração de seu autor sobre os fatos sociais. Assim, pode-se expor: "A charge é um discurso socio-historicamente situado que está em relação com fatos sociais que lhe são contemporâneos. De toda forma, a arquitetura dos elementos verbais e visuais da charge emite determinado ponto de vista, isto é, emite os juízos de valor que um locutor específico compõe sobre o mundo em que está circunscrito. Explique qual é a valoração veiculada nas charges publicadas por Latuff. Sustente os efeitos de sentido projetados a partir dos próprios elementos que as constituem. Observe que embora tenham sido criadas em momentos distintos $(2014$ e 2015) sua relação pode compor uma crítica maior do que a já mobilizada por cada uma delas".

As sugestões de exploração da compreensão leitora aqui mencionadas são nesses termos propriamente ideias porque o trabalho com charges deve ser sempre atualizado quanto aos discursos sociais em debate, uma vez que esse gênero origina-se justamente a partir de discursos outros - e porque, sem estar a par dos discursos sociais em circulação, não é possível chegar a uma compreensão leitora profunda desse gênero. Ademais, o professor tem de ter em conta aspectos como a série em que pensa trabalhar; as temáticas oportunas para discutir. Toda atividade deve ser adequada ao grupo que se aplica para que possa ser significativa.

Outrossim, cabe ressaltar que os instrumentos de pesquisa (como o aqui demonstrado com a ajuda dos Formulários Google) devem ser testados, avaliados e inspecionados para comprovar sua eficácia. Quem sabe outro artigo conte com a etapa de implementação dessas atividades a um público específico e se tenham dados para comprovar a interface sugerida, bem como os resultados no que tange à compreensão de charges - gênero complexo que demanda uma série de requisitos do leitor.

\section{Conclusão}

O presente trabalho teve como objetivo compreender a charge sob a perspectiva dos postulados de Bakhtin e da psicolinguística, principalmente à luz das noções de signo ideológico, gêneros discursivos, vozes sociais e do conceito de compreensão leitora, respectivamente. A partir do estudo de duas charges de Carlos Latuff, publicadas uma em 2014 e outra em 2015 no endereço eletrônico Sul 21, buscou-se entender a atividade enunciativa que as constitui: quais recursos são mobilizados para a edificação de seus sentidos. Para tanto, verificou-se como se deram as relações dialógicas entre as charges e os enunciados anteriores que com elas se relacionam para se constituir como gênero na cadeia da comunicação discursiva, visando a montar uma sugestão de trabalho com charge a partir de uma ferramenta on-line.

Com as discussões em torno dos sentidos construídos, foi possível perceber que todo discurso estabelece uma necessária relação com outros 
discursos, desencadeando diferentes sentidos. Talvez o que particularize a charge é que, muitas vezes de modo velado, ela recupera valorativamente temas da atualidade que, se não identificados pelo leitor, prejudicarão o entendimento dos sentidos veiculados, especialmente quanto ao seu projeto enunciativo de estabelecer uma crítica sobre um dado tema.

Por fim, pôde-se perceber que a charge torna possível um interessante trabalho com língua portuguesa por permitir a abordagem de aspectos referentes à linguagem em uso, a partir da relação de elementos verbais e não verbais em tensão com discursos sociais diversos. Isso viabiliza a discussão em torno dos sentidos construídos quando se relacionam elementos dados e novos a partir da valoração que colore todo discurso.

\section{Referências}

BAKTHIN, M. Gêneros do Discurso (1952-1953). In: Estética da Criação Verbal (1979). Trad. Paulo Bezerra. 6. ed. São Paulo: Martins Fontes, 2011.

BAKHTIN, M/VOLOCHÍNOV, V. N. Marxismo e filosofia da linguagem (1929). Trad. Michel Laud e Yara Frateschi. São Paulo: Hucitec, 2009.

BALIEIRO JR, Ari Pedro. Psicolingüística. In: MUSSALIM, Fernanda; BENTES, Anna Cristina Bentes. Introdução à linguística: domínios e fronteiras. 3. ed. São Paulo: Cortez, 2003.

BUBNOVA, Tatiana. Prólogo. In: BAJTIN, Mijail. Yo también soy: fragmentos del outro. Ciudad Autónoma de Buenos Aires: EGodot Argentina, 2015.

BRASIL. Secretaria de Educação Fundamental. Parâmetros Curriculares Nacionais: terceiro e quarto ciclos do ensino fundamental: língua portuguesa/Secretaria de Educação Fundamental. Brasília: MEC/SEF, 1998.

BRASIL, Ministério da Educação. Parâmetros Curriculares Nacionais. Disponível em: $<$ www.mec.com.br>. Acesso em: jun. 2013.

BRASIL, Ministério da Educação. Orientações Curriculares para o ensino médio. Disponível em <http://portal.mec.gov.br/seb/arquivos/pdf/book_volume_01_internet. pdf>. Acesso em: jun. 2013.
FARACO, Carlos Alberto. Linguagem e diálogo: as ideias linguísticas do Círculo de Bakhtin. São Paulo: Parábola, 2009.

VOLOCHÍNOV, V. A. a palavra na vida e na poesia. Introdução ao problema da poética sociológica (1926). In: BAKHTIN, M. Palavra própria e palavra outra na sintaxe da enunciação. São Carlos: Pedro e João Editores, 2011.

TOMICH, Lêda Maria Braga. Desvelando o processo de compreensão leitora: protocolos verbais na pesquisa em leitura. Signo. Santa Cruz do Sul, v. 32, n. 53, p. 42-53, dez. 2007. Disponível em: <https://www.researchgate.net/publication/277159515_DESVELANDO_O_ PROCESSO_DE_COMPREENSAO_LEITORA_PROTOCOLOS_VERBAIS_NA_PESQUISA_EM LEITURA>. Acesso em: 06 abr. 2016.

KLEIMAN, Leitura: ensino e pesquisa. Campinas: Pontes, 2008.

SMITH, Frank. Leitura significativa. Trad. Beatriz Affonso Neves. Porto Alegre: ARTMED, 1999.

Compreendendo a leitura: uma análise psicolinguística da leitura e do aprender a ler. Trad. Daise Batista. Porto Alegre: ARTMED, 2003.

SLAMA-CAZACU, Tatiana. Psicolingüística aplicada ao ensino de línguas. Trad. Leonor Scliar-Cabral. São Paulo: Pioneira, 1979.

PEREIRA, Vera Wannmacher. Estratégias de E-book. In: Signo. Santa Cruz do Sul, v. 34 n. 56, p. 80-89, dez. 2009. Disponível em: <http://online.unisc.br/seer/index.php/signo/ article/view/784/686>. Acesso em: 07 abr. 2016>.

PEREIRA, Vera Wannmacher. A predição na teia de estratégias de compreensão leitora. In: Confluência, Rio de Janeiro, v. 1, p. 81-91, 2012. Disponível em: <http://llp.bibliopolis. info/confluencia/pdf/291.pdf>. Acesso em: 08 abr. 2016.

Recebido em 25/04/2016.

Aceito em 07/06/2016. 